\title{
Hydraulic performance of Piano Key Weir
}

\author{
Dr.Adil M. Raheem ${ }^{1}$, Tara Haydar Aurahman ${ }^{2}$ \\ \{dr_adilraheem@yahoo.com ${ }^{1}$,tarahaydar86@gmail.com² $\}$
}

Assistant professor, College of Engineering, Al-Kitab University-Altun Kopri ${ }^{1}$, lecturer in Dam and Water Resources Engineering, College of Engineering, University of Salahaddin, Erbil ${ }^{2}$

\begin{abstract}
PKWs are considered an effective solution for dam designs which require either high specific discharge efficiency or low reservoir level. The influence of piano key weir geometry on discharge capacity was studied and for this purpose, twenty-seven physical models of two types(Aand D) of piano key weir and rectangular labyrinth weir(RLW) were constructed and tested, Dimensional analysis was carried out to find the influence of the geometric parameter on discharge capacity ratio .Prediction equations for discharge capacity ratio were found and compared with equatins for other investigators.The discharge capacity ratio of PKW was increased with increasing the value of (Wi/Wo). For PKW type A, the discharge capacity ratio was increased by (25\%) with increasing the value of Wi/Wo from 0.5 to 2 , increasing the head over PKW, leds the discharge capacity ratio to be decreased.and variation in the height of PKW (P) doesn't affect the hydraulic performance of PKW . The discharge capacity ratio of PKW increased by $(27 \%)$ with increasing the value of $(\mathrm{L} / \mathrm{W})$ from 3 to 7 . PKW type A was founded more efficient than the other types.

Keywords: hydraulic, weirs, piano, flow, discharge.
\end{abstract}

\section{Introduction}

The discharge capacity of free crest or ungated over fall spillways or weirs is directly proportional to the length of the crest for a given upstream head. Its length can be increased by using curved, undulated or corrugated weirs instead of straight linear weirs, which increase the discharge for a given head. In recent year's people have developed different types of weirs with different shapes and all of them aimed to increase the discharge capacity. The main advantages of the PK weir regarding labyrinth weirs are its reduced footprint. PKW was developed specifically for smaller control structure footprint applications. For some spillway applications, the control structure footprint length $(B)$ and width $(W)$ may be limited, e.g. narrow dam crest, for such cases, some of the benefits of the traditional labyrinth weir are lost, and alternative non-linear weir designs need to be considered.[1][9]. Many of the current dams need spillway reconstruction to increase their hydraulic efficiency, development, improvement in hydrological analysis with a modern technique for discharge estimation and for a higher requirement of dam safety, For this purpose, the new innovative shape of labyrinth weir called PKW is an interesting option. [11].

Goulours dam in France was the prototype of the Piano Key Weir which was constructed and completed in 2006 and the second prototype of PKW was constructed at Saint-Marc dam in France and completed in 2008. Until today little research has been conducted on Piano Key Weir, as they 
are considered as nonlinear weirs that have been introduced recently. Rectangular types of PKW have a simple crest layout with cantilever overhung because it is the easiest to use when varying the shape according to the plan of the weir. However, the most advantageous form corresponds to the rectangular symmetrical form. [4], [5]

Due, to a large number of geometric parameters and a limited understanding of their effects on discharge efficiency, there are no generally accepted standard PK weir design procedures available [1].

Comparison between the PKW and labyrinth weirs gives the following advantages:

- PKW can be installed directly on top of the gravity dams because of its reduced footprint [6].

- Developed crest length is relative to the limited weir width. This provides a high discharge capacity and the overhung in inlet and outlet key floors instead of the horizontal-vertical floor of labyrinth weirs which improves their hydraulic capacity [1], [2], [4].

- Relative to trapezoidal labyrinth weirs, PKW geometries are better at nappe aeration, due to the cantilever or overhang geometry. This is necessary to avoid undesirable vibrations in the weir structure. [1]

- Piano Key Weir is a more efficient and cost-effective solution for increasing the flood releasing capacity of existing dams. [3], [7], [12]

To obtain the effect of geometrical parameters on the hydraulic performance of Piano Key Weir, an experimental study was carried out. The influence of the main geometric parameters on the PKW discharge capacity using dimensionless group ratio terms was the main goal of the current study.

\section{Theoretical Considerations}

Comparison between the PKW and sharp-crested weir was carried out to analyze the PKW efficiency. Piano Key Weir (PKW) tends to behave like a linear weir as the upstream head increases. Consequently, for analysis purposes the discharge capacity ratio (r)between the rectangular sharp-crested weir discharge $\left(\mathrm{Q}_{\mathrm{Sh}}\right)$ and $\mathrm{PKW}$ discharge $\left(\mathrm{Q}_{\mathrm{PKW}}\right)$ have been adopted.

There are two approaches which are common to describe the PKW discharge:

1. Deriving a specific discharge coefficient using the Poleni equation. [5], [9], [13]

$$
Q_{P K W}=\frac{2}{3} C_{d} \sqrt{2 g} H_{t}^{\frac{3}{2}} L
$$

and

$$
\mathrm{H}_{\mathrm{t}}=\frac{v_{o}{ }^{2}}{2 g}+\text { ho } \quad, \quad \text { and ho }=\text { yo-P } \quad \ldots . . .
$$

where:

(g) is the gravity acceleration, (Ht) is the upstream head above weir crest as shown in figure 1. QPKW is piano key weir discharge capacity and Cd is discharge coefficient of PKW.

2. Comparing between the discharge of PKW and discharge of sharp-crested weir Qsh yield. [10] 


$$
r=\frac{Q_{P K W}}{Q_{S}}=\frac{C_{d} L_{e f f} \sqrt{2 g} H t^{\frac{3}{2}}}{C_{d} W \sqrt{2 g} H t^{\frac{3}{2}}}=\frac{L_{e f f}}{W} \ldots
$$

The analysis was made by comparison of the discharge enhancement ratio $(r)$ versus $H / P$. Only values of $H / P$ higher than 0.1 were considered to avoid capillarity effects. The discharge coefficient $C_{\text {sh }}$ for sharp-crested weir was assumed to be constant as 0.42. [10]

$L$ is the length of the crest of PKW, to keep the same discharge $L$ was decreased and the head increased. The discharge of e PKW was measured in the laboratory, while the theoretical discharge of a sharp-crested weir was calculated according to the measured hydraulic head over the PKW. Leff is the effective crest length of the PKW that theoretically contributes to the flow over PKW.

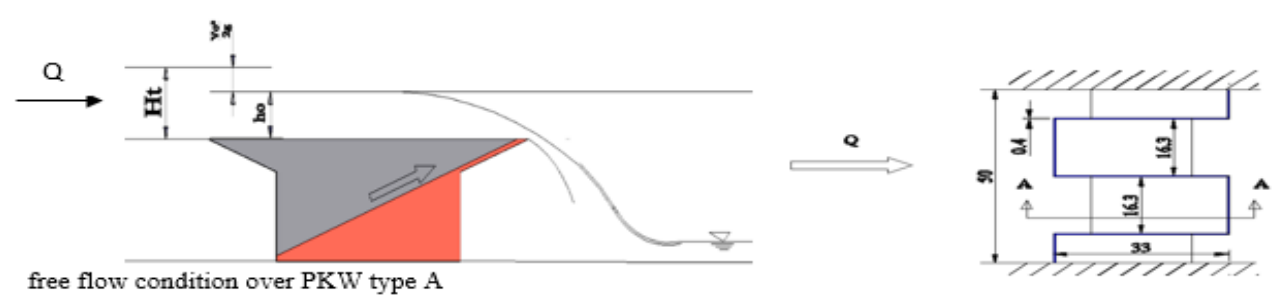

Figure 1. Free flow condition over PKW.

\section{Dimensional analysis of piano key weir}

Dimensional analysis is a powerful tool for solving many theoretical and experimental physical studies. Dimensional analysis was carried out by using Buckingham's pi-theorem to achieve a rational correlation between the dimensionless group terms. To determine the parameter that affects the discharge coefficient $(\mathrm{Cd})$, the determination of the different dimensionless group terms can be carried out using the dimensional analysis approach. 


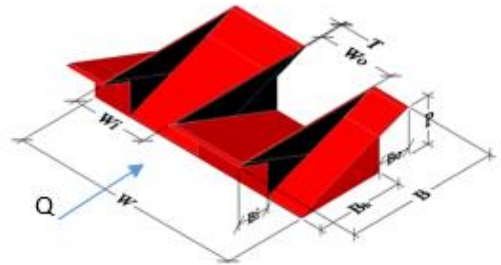

Piano key weir type A

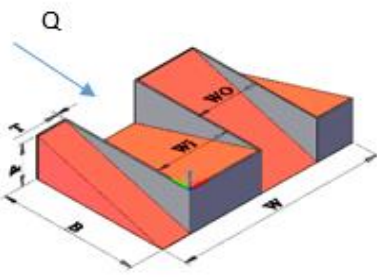

Piano key weir type D

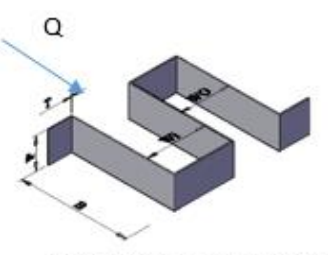

Rectangular labyrinth weir

Figure 2. main geometric parameters of piano key weirs.

Discharge over piano key weir depends on the following parameters:

Geometry parameters which can be described as shown in Fig 2 were; Height of the piano key weir (p), Width of the piano key weir (W), Head over the piano key weir $(\mathrm{H})$, Total development length (L), Width of inlet key (Wi), Width of outlet key (Wo), Lateral length of the piano key weir (B), Length of upstream overhang (Bi), Length of downstream overhang (Bo), Thickness of the wall (T), the slope of inlet $\operatorname{key}(\operatorname{Sin})$, and slope of outlet key $\left(S_{\text {out }}\right)$, Kinematic parameters which can be described as kinematic viscosity $(\boldsymbol{V})$, Gravitational acceleration $(\mathrm{g})$ and the dynamic parameters was Surface tension ( $\sigma$ ) and Mass density $(\rho)$.

To describe the free flow over the piano key weir, the physical phenomena can be expressed in general forms as:

$$
Q=f\left(\rho, g, v, \sigma, H, L, P, W, W i, W o, B, B i, B o, T, R, S_{\text {in }}, S_{\text {out }}\right)
$$

By using Buckingham pi theorem, with taking $\rho, \mathrm{g}$ and $\mathrm{H}$ as repeating variables, the following $\pi$ terms can be determined, and due to the constant value of wall thickness $(T=0.4 \mathrm{~cm})$, therefore $(\mathrm{T})$ was not included in the general form of the flow dimension equation.

$$
\frac{Q}{\sqrt{g} H^{\frac{3}{2}}}=\phi\left[F r, W e, \frac{H t}{P}, \frac{L}{W}, \frac{B}{P}, \frac{W i}{W o}, \frac{B i}{B o}, S_{\text {in }}, S_{\text {out }}\right]
$$

Froude number and Weber were neglected due to the condition of the flow which is subcritical and with no surface tension consideration. Since the slope of the inlet and outlet key were taken as constant and also the length of the overhung in upstream as equal to the length of the overhang in downstream so $\mathrm{Bi} / \mathrm{Bo}$ and $\mathrm{Si}$, So can be neglected, therefore equation 5 becomes:

$$
C_{d}=\phi\left[\frac{H t}{P}, \frac{L}{W}, \frac{B}{P}, \frac{W_{i}}{W o}\right]
$$




\section{Materials and Methods:}

A series of tests were conducted on models of the piano key weir in the engineering laboratory using PKW with (1.5 unit of inlet key+1.5 unit of outlet key) and PKW with (2 two-unit inlet key +2 unit outlet key) with a constant value of $(\mathrm{L} / \mathrm{W}=3),(\mathrm{Wi} / \mathrm{Wo}=1)$ and $(\mathrm{P}=10 \mathrm{~cm})$ and from the experimental result it was found that the PKW of 1.5 unit was more efficient than the PKW with 2unit regarding the discharge capacity ratio so, one and a half unit model $(1.5$ inlet key +1.5 outlet key) was constructed over a constant width $(\mathrm{W}=0.5 \mathrm{~m})$ for all PKW types.

For type A piano key weir, which had upstream and downstream overhangs, five models of different value of $(\mathrm{Wi} / \mathrm{Wo})$ as dimensionless group terms were constructed with values of $(0.5,0.8,1,1.25$ and 2) while the other parameter was held to be constant such as $(\mathrm{L} / \mathrm{W}=3),(\mathrm{P}=10 \mathrm{~cm})(\mathrm{T}=0.4 \mathrm{~cm})(\mathrm{B}=33 \mathrm{~cm})$, two models of different values of $(\mathrm{L} / \mathrm{W})$ as dimensionless group terms were constructed with the values of (5and 7) and the other parameters were held to be constant such as $(\mathrm{Wi} / \mathrm{Wo}=1),(\mathrm{P}=10 \mathrm{~cm})(\mathrm{T}=0.4 \mathrm{~cm})(\mathrm{B}=33 \mathrm{~cm})$, two models of different value of $(\mathrm{P})$ as dimensionless group terms were constructed with the values of (12 and 14) and the other parameters were held to be constant [ as illustrated in Table 1].

Table1 Dimensions of nine tested Models of PKW type A

\begin{tabular}{|c|c|c|c|c|c|c|c|c|c|c|c|}
\hline $\begin{array}{c}\text { Model } \\
\text { No. }\end{array}$ & L/W & Wi/Wo & Wi & Wo & L & P(cm) & T(cm) & B(cm) & Bi & Bo & $\mathbf{B}_{\mathbf{b}}$ \\
\hline $\mathbf{1}$ & $\mathbf{3}$ & $\mathbf{1}$ & $\mathbf{1 6 . 3}$ & $\mathbf{1 6 . 3}$ & $\mathbf{1 . 5}$ & $\mathbf{1 0}$ & $\mathbf{0 . 4}$ & $\mathbf{3 3}$ & $\mathbf{7}$ & $\mathbf{7}$ & $\mathbf{1 9}$ \\
\hline $\mathbf{2}$ & $\mathbf{3}$ & $\mathbf{0 . 5}$ & $\mathbf{1 0 . 8}$ & $\mathbf{2 1 . 7}$ & $\mathbf{1 . 5}$ & $\mathbf{1 0}$ & $\mathbf{0 . 4}$ & $\mathbf{3 3}$ & $\mathbf{7}$ & $\mathbf{7}$ & $\mathbf{1 9}$ \\
\hline $\mathbf{3}$ & $\mathbf{3}$ & $\mathbf{0 . 8}$ & $\mathbf{1 4 . 5}$ & $\mathbf{1 8}$ & $\mathbf{1 . 5}$ & $\mathbf{1 0}$ & $\mathbf{0 . 4}$ & $\mathbf{3 3}$ & $\mathbf{7}$ & $\mathbf{7}$ & $\mathbf{1 9}$ \\
\hline $\mathbf{4}$ & $\mathbf{3}$ & $\mathbf{1 . 2 5}$ & $\mathbf{1 8}$ & $\mathbf{1 4 . 5}$ & $\mathbf{1 . 5}$ & $\mathbf{1 0}$ & $\mathbf{0 . 4}$ & $\mathbf{3 3}$ & $\mathbf{7}$ & $\mathbf{7}$ & $\mathbf{1 9}$ \\
\hline $\mathbf{5}$ & $\mathbf{3}$ & $\mathbf{2}$ & $\mathbf{2 1 . 7}$ & $\mathbf{1 0 . 8}$ & $\mathbf{1 . 5}$ & $\mathbf{1 0}$ & $\mathbf{0 . 4}$ & $\mathbf{3 3}$ & $\mathbf{7}$ & $\mathbf{7}$ & $\mathbf{1 9}$ \\
\hline $\mathbf{6}$ & $\mathbf{3}$ & $\mathbf{1}$ & $\mathbf{1 6 . 3}$ & $\mathbf{1 6 . 3}$ & $\mathbf{1 . 5}$ & $\mathbf{1 2}$ & $\mathbf{0 . 4}$ & $\mathbf{3 3}$ & $\mathbf{7}$ & $\mathbf{7}$ & $\mathbf{1 9}$ \\
\hline $\mathbf{7}$ & $\mathbf{3}$ & $\mathbf{1}$ & $\mathbf{1 6 . 3}$ & $\mathbf{1 6 . 3}$ & $\mathbf{1 . 5}$ & $\mathbf{1 4}$ & $\mathbf{0 . 4}$ & $\mathbf{3 3}$ & $\mathbf{7}$ & $\mathbf{7}$ & $\mathbf{1 9}$ \\
\hline $\mathbf{8}$ & $\mathbf{5}$ & $\mathbf{1}$ & $\mathbf{1 6 . 3}$ & $\mathbf{1 6 . 3}$ & $\mathbf{2 . 5}$ & $\mathbf{1 0}$ & $\mathbf{0 . 4}$ & $\mathbf{6 7}$ & $\mathbf{2 3}$ & $\mathbf{2 3}$ & $\mathbf{2 1}$ \\
\hline $\mathbf{9}$ & $\mathbf{7}$ & $\mathbf{1}$ & $\mathbf{1 6 . 3}$ & $\mathbf{1 6 . 3}$ & $\mathbf{3 . 5}$ & $\mathbf{1 0}$ & $\mathbf{0 . 4}$ & $\mathbf{1 0 0}$ & $\mathbf{4 0}$ & $\mathbf{4 0}$ & $\mathbf{2 0}$ \\
\hline
\end{tabular}

For type D piano key weir which had no upstream and downstream overhangs, five models of different values of (Wi/Wo) as dimensionless group terms were constructed with values of $(0.5,0.8$, $1,1.25$ and 2) while the other parameter was held to be constant such as $(\mathrm{L} / \mathrm{W}=3),(\mathrm{P}=10 \mathrm{~cm})$, $(\mathrm{T}=0.4 \mathrm{~cm}),(\mathrm{B}=33 \mathrm{~cm})$. Two models of different values of $(\mathrm{L} / \mathrm{W})$ as dimensionless group terms were constructed with the values of (5 and 7) and the other parameters were held to be constant such as $(\mathrm{Wi} / \mathrm{Wo}=3),(\mathrm{P}=10 \mathrm{~cm}),(\mathrm{T}=0.4 \mathrm{~cm}),(\mathrm{B}=33 \mathrm{~cm})$. Two models of different value sof $(\mathrm{P})$ as dimension group terms were constructed with the values of $(12 \mathrm{~cm}$ and $14 \mathrm{~cm})$ and the other parameters were held to be constant such as $(\mathrm{Wi} / \mathrm{Wo}=3),(\mathrm{L} / \mathrm{W}=3),(\mathrm{T}=0.4 \mathrm{~cm}),(\mathrm{B}=33)$ [ as illustrated in Table 2].

Table 2 Dimensions of the nine tested Models of PKW type D 


\begin{tabular}{|c|c|c|c|c|c|c|c|c|c|c|c|}
\hline $\begin{array}{c}\text { Model } \\
\text { No. }\end{array}$ & L/W & Wi/Wo & Wi & Wo & $\mathbf{L}$ & $\mathbf{P}(\mathbf{c m})$ & $\mathbf{T}(\mathbf{c m})$ & $\mathrm{B}(\mathbf{c m})$ & $\mathbf{B i}$ & Bo & $\mathbf{B b}$ \\
\hline 1 & 3 & 1 & 16.3 & 16.3 & 1.5 & 10 & 0.4 & 33 & 0 & 0 & 33 \\
\hline 2 & 3 & 0.5 & 10.8 & 21.7 & 1.5 & 10 & 0.4 & 33 & 0 & 0 & 33 \\
\hline 3 & 3 & 0.8 & 14.5 & 18 & 1.5 & 10 & 0.4 & 33 & $\mathbf{0}$ & $\mathbf{0}$ & 33 \\
\hline 4 & 3 & 1.25 & 18 & 14.5 & 1.5 & 10 & 0.4 & 33 & $\mathbf{0}$ & $\mathbf{0}$ & 33 \\
\hline 5 & 3 & 2 & 21.7 & 10.8 & 1.5 & 10 & 0.4 & 33 & 0 & O & 33 \\
\hline 6 & 3 & 1 & 16.3 & 16.3 & 1.5 & 12 & 0.4 & 33 & 0 & 0 & 33 \\
\hline 7 & 3 & 1 & 16.3 & 16.3 & 1.5 & 14 & 0.4 & 33 & 0 & $\mathbf{0}$ & 33 \\
\hline 8 & 5 & 1 & 16.3 & 16.3 & 2.5 & 10 & 0.4 & 67 & $\mathbf{0}$ & $\mathbf{0}$ & 67 \\
\hline 9 & 7 & 1 & 16.3 & 16.3 & 3.5 & 10 & 0.4 & 100 & 0 & 0 & 100 \\
\hline
\end{tabular}

For rectangular labyrinth weirs (RLW) which had no upstream and downstream overhangs or upstream and downstream slopes, five models of different values of (Wi/Wo) as dimensionless group terms were constructed with values of $(0.5,0.8,1,1.25$ and 2$)$ while the other parameter was held to be constant such as $(\mathrm{L} / \mathrm{W}=3),(\mathrm{P}=10 \mathrm{~cm}),(\mathrm{T}=0.4 \mathrm{~m}),(\mathrm{B}=33 \mathrm{~cm})$. Two models of different values of $(\mathrm{L} / \mathrm{W})$ as dimensionless group terms were constructed with the values of $(5$ and 7) and the other parameters were held to be constant such as $(\mathrm{Wi} / \mathrm{Wo}=3),(\mathrm{P}=10 \mathrm{~cm})$, $(\mathrm{T}=0.4 \mathrm{~cm}),(\mathrm{B}=33 \mathrm{~cm})$. Two models of different values of $(\mathrm{P})$ as dimension group terms were constructed with the values of $(12 \mathrm{~cm}$ and $14 \mathrm{~cm})$ and the other parameters were held to be constant such as $(\mathrm{Wi} / \mathrm{Wo}=3),(\mathrm{L} / \mathrm{W}=3)(\mathrm{T}=0.4)(\mathrm{B}=33)$ as shown in table 3.

Table 3 Dimensions of the nine tested Models of RLW

\begin{tabular}{|c|c|c|c|c|c|c|c|c|c|c|}
\hline $\begin{array}{c}\text { Model } \\
\text { No. }\end{array}$ & L/W & Wi/Wo & Wi & Wo & L & P $(\mathrm{cm})$ & $\mathrm{t}(\mathrm{cm})$ & $\mathrm{B}(\mathrm{cm})$ & $\mathrm{Si}$ & So \\
\hline $\mathbf{1}$ & $\mathbf{3}$ & $\mathbf{1}$ & $\mathbf{1 6 . 3}$ & $\mathbf{1 6 . 3}$ & $\mathbf{1 . 5}$ & $\mathbf{1 0}$ & $\mathbf{0 . 4}$ & $\mathbf{3 3}$ & $\mathbf{0}$ & 0 \\
\hline $\mathbf{2}$ & $\mathbf{3}$ & $\mathbf{0 . 5}$ & $\mathbf{1 0 . 8}$ & $\mathbf{2 1 . 7}$ & $\mathbf{1 . 5}$ & $\mathbf{1 0}$ & $\mathbf{0 . 4}$ & $\mathbf{3 3}$ & $\mathbf{0}$ & 0 \\
\hline $\mathbf{3}$ & $\mathbf{3}$ & $\mathbf{0 . 8}$ & $\mathbf{1 4 . 5}$ & $\mathbf{1 8}$ & $\mathbf{1 . 5}$ & $\mathbf{1 0}$ & $\mathbf{0 . 4}$ & $\mathbf{3 3}$ & $\mathbf{0}$ & 0 \\
\hline $\mathbf{4}$ & $\mathbf{3}$ & $\mathbf{1 . 2 5}$ & $\mathbf{1 8}$ & $\mathbf{1 4 . 5}$ & $\mathbf{1 . 5}$ & $\mathbf{1 0}$ & $\mathbf{0 . 4}$ & $\mathbf{3 3}$ & $\mathbf{0}$ & 0 \\
\hline $\mathbf{5}$ & $\mathbf{3}$ & $\mathbf{2}$ & $\mathbf{2 1 . 7}$ & $\mathbf{1 0 . 8}$ & $\mathbf{1 . 5}$ & $\mathbf{1 0}$ & $\mathbf{0 . 4}$ & $\mathbf{3 3}$ & $\mathbf{0}$ & 0 \\
\hline $\mathbf{6}$ & $\mathbf{3}$ & $\mathbf{1}$ & $\mathbf{1 6 . 3}$ & 16.3 & $\mathbf{1 . 5}$ & 12 & $\mathbf{0 . 4}$ & $\mathbf{3 3}$ & $\mathbf{0}$ & 0 \\
\hline $\mathbf{7}$ & $\mathbf{3}$ & $\mathbf{1}$ & $\mathbf{1 6 . 3}$ & 16.3 & $\mathbf{1 . 5}$ & 14 & $\mathbf{0 . 4}$ & $\mathbf{3 3}$ & $\mathbf{0}$ & 0 \\
\hline $\mathbf{8}$ & $\mathbf{5}$ & $\mathbf{1}$ & $\mathbf{1 6 . 3}$ & $\mathbf{1 6 . 3}$ & $\mathbf{2 . 5}$ & $\mathbf{1 0}$ & $\mathbf{0 . 4}$ & $\mathbf{6 7}$ & $\mathbf{0}$ & 0 \\
\hline $\mathbf{9}$ & $\mathbf{7}$ & $\mathbf{1}$ & $\mathbf{1 6 . 3}$ & $\mathbf{1 6 . 3}$ & $\mathbf{3 . 5}$ & $\mathbf{1 0}$ & $\mathbf{0 . 4}$ & $\mathbf{1 0 0}$ & $\mathbf{0}$ & 0 \\
\hline
\end{tabular}


The experimental runs were carried out using flumes at the hydraulic laboratory of engineering college in Salahaddin university. Water was drawn from the underground storage tank by an electrically driven centrifugal pump through a 6-inch diameter steel pipe to the overhead tank providing a total discharge of $(50 \mathrm{lit} / \mathrm{sec})$. The discharge in the flume was measured utilizing a Vnotch weir located at the end of the overhead tank. The head of water above the V-notch was measured by a point guage with a Vernier scale of $0.05 \mathrm{~mm}$ accuracy, located $80 \mathrm{~cm}$ upstream of the $\mathrm{V}$-notch weir and placed in a small box tank fixed to the right side of the overhead tank. To calibrate the discharge measured in terms of the V-notch weir water depth, the water depth above the Vnotch was measured with values between $5 \mathrm{~cm}$ to $26 \mathrm{~cm}$. For particular values of water depth, the measuring tank under the weir was placed and a reasonable volume for various times was recorded. To get accurate results, the procedure was repeated twice for each water depth. Several records were measured for different water depth over the V-notch weir. A good relationship between the discharge and water depth over the V-notch weir was obtained through the observed data. The following relationship was obtained which has a determination coefficient $\left(\mathrm{R}^{2}\right)$ of 0.999 : [8]

$$
\mathrm{Qv}=0.0195 \mathrm{~h}_{\mathrm{v}}^{2.398 \quad \ldots . . .}
$$

Where Qv: Discharge over the V-notch in lit/sec, and hv: head of water above the V-notch weir in $\mathrm{cm}$. The testing program was done by allowing the flow to be passed through each model of piano key weir type A, type D and rectangular labyrinth weir. In each state of flow, the discharge is gradually increased such that the behaviour of the flow is recognized. Each flow state consists of several runs. For each run, the depth of water above the V-notch weir (hv) and the corresponding uniform water depth in the canal upstream of the tested model (yo) were measured. Discharge over the piano key weir with developed crest length $(\mathrm{L}=150 \mathrm{~cm})$ and width of the channel $(\mathrm{W}=50 \mathrm{~cm})$ was equal to the measured discharge over the $\mathrm{v}$-notch $(\mathrm{Qv})$, the discharge coefficient $\mathrm{Cd}$ was calculated as:

$$
\frac{\mathrm{Q}_{\mathrm{PKW}}}{\mathrm{C}_{\mathrm{d}}}=\frac{2}{3} \mathrm{~L} \sqrt{2 \mathrm{~g}} * \mathrm{Ht}^{\frac{3}{2}}
$$

Fig. 3 shows the experimental runs for different piano key weirs (a. PKW type A, b. PKW type D, c. Labyrinth KW, d. Experimental Channel.
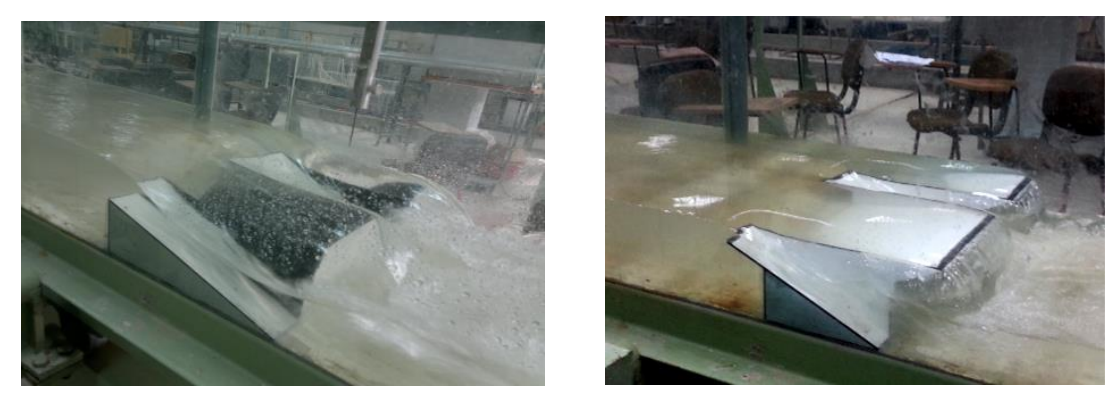
A-left. Typical model of a piano key weir type A with wi/wo= 1 weir type D
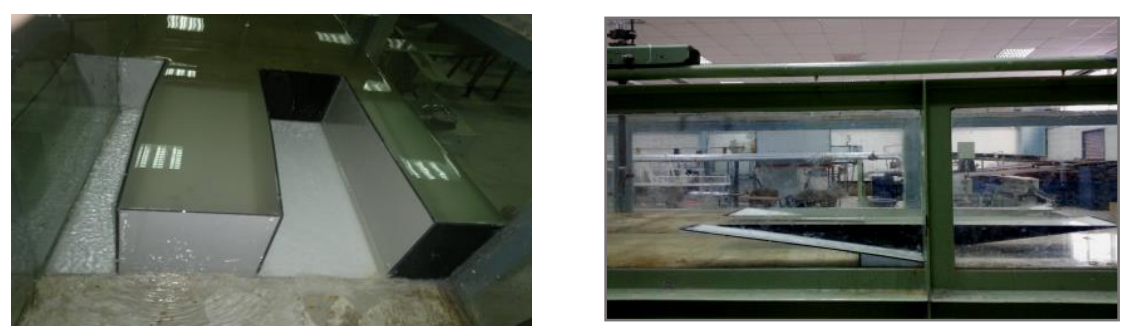

C-left. A typical model of a labyrinth piano key weir; D-right. Experimental Channel used in the study

Fig. 3 Experimental runs of different types of PKW

\section{Results and Discussion:}

To analyze the experimental data, the influence of each variable in the dimensional analysis term was discussed to establish a reasonable relationship between them. The best information on each variable which affects the discharge capacity ratio and discharge coefficient could be explained and investigated, leading to finding a mathematical relationship describing the two above factors.

As defined previously, the discharge capacity ratio ( $r$ ) was the ratio between the discharges of PKW and the discharge of the sharp-crested weir, many factors influence this ratio such as (L/W), (Wi/Wo), $(\mathrm{Ht} / \mathrm{P})$ and $(\mathrm{B} / \mathrm{P})$. The effect of each factor can be discussed and analyzed separately as in the following items:

\section{Influence of $(\mathrm{L} / \mathrm{W})$ term on discharge capacity ratio}

The developed length ratio (L/W) was the most important parameter influencing the efficiency of PKW. For piano key weir type A, D and labyrinth, the relationship between (r) and (Ht/p) were drawn as shown in figure 4 for various values of $(\mathrm{L} / \mathrm{W})$ ratio $(\mathrm{L} / \mathrm{W}=3,5,7)$ while keeping the other parameters constant such as $\left(\mathrm{P}=10 \mathrm{~cm}\right.$ and $\left.\mathrm{Wi} / \mathrm{Wo}_{\mathrm{O}}=1\right)$. From these figures, the capacity discharge ratio will be decreased as $\mathrm{Ht} / \mathrm{P}$ was increased. This is because when $\mathrm{Ht} / \mathrm{P}$ was increased, the effective length of the weir was decreased, so decreasing in Leff will cause a decrease in discharge capacity ratio $(r=$ Leff $/ \mathrm{W})$. Therefore, the discharge capacity for PKW will be decreased due to the decrease in discharge capacity ratio as shown in the relationship ( $\mathrm{r}=\mathrm{QPKW} / \mathrm{Qsh})$. Furthermore, increasing of the head over the PKW decrease Leff (effective crest length) which lead to the interference of overflowing layer, changing the value of $\mathrm{L} / \mathrm{W}$ from 3 to 7 for the same $\mathrm{Ht} / \mathrm{P}$ value leads to increase in the (r) ratio by $27 \%$. 


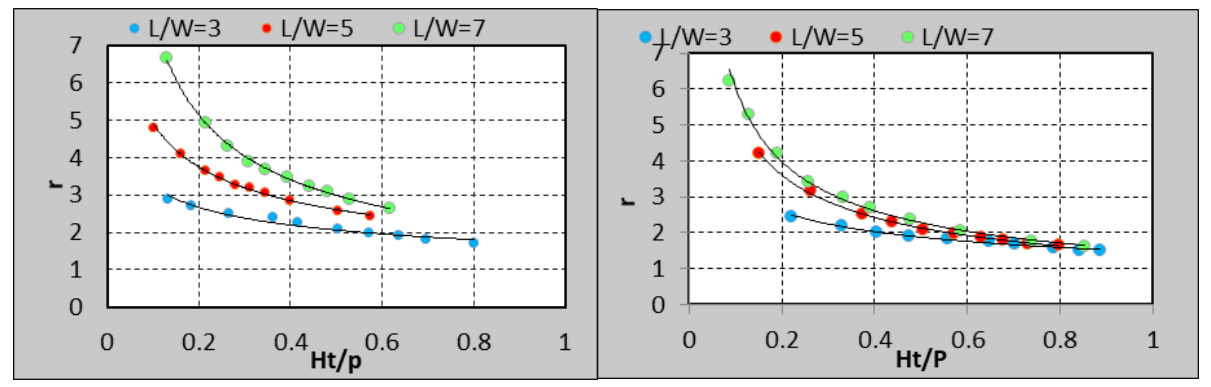

a-left Effect of (L/W) on discharge capacity ratio(r) ratio (r) for PKW type A b-right Effect of $(\mathrm{L} / \mathrm{W})$ on discharge capacity for PKW type D

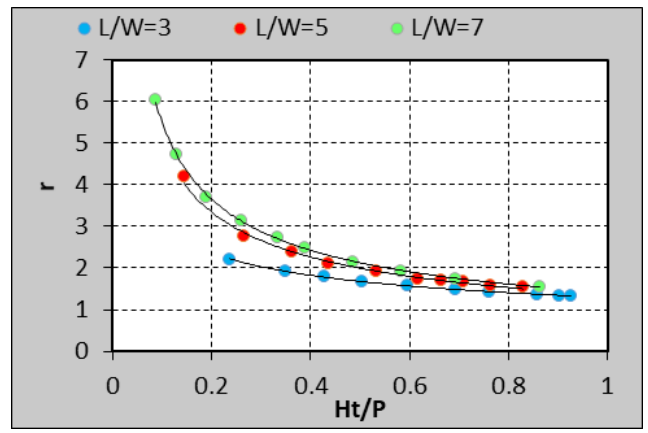

c. Effect of (L/W) on discharge capacity ratio(r) for RLW

Figures 4 Influence of ( $\mathrm{L} / \mathrm{W}$ ) ratios on discharge capacity ratio (r) for a different type of piano key weirs.

\section{Influence of (Wi/Wo) on discharge capacity ratio (r)}

To show the influence of the width ratio between the inlet and outlet key on the discharge capacity ratio (r), a relationship between discharge capacity ratio (r) and dimensionless pi group term $(\mathrm{Ht} / \mathrm{P})$ for several types of PKW models was investigated considering the different value of Wi/Wo (Wi/Wo=0.5, 0.8, 1, 1.25, and 2).

For different PKW type, the relationship between the discharge capacity ratio (r) and the parameter $\mathrm{Ht} / \mathrm{P}$ for different values of $\mathrm{Wi} / \mathrm{Wo}$ was shown in figures 5 . The capacity discharge ratio (r) was decreased when $(\mathrm{Ht} / \mathrm{P})$ increased due to the effect in decreasing (L) value, and the ratio between inlet and outlet widths (Wi/Wo) reveals a higher efficiency when this ratio was more than one $(\mathrm{Wi} / \mathrm{Wo}>1)$ rather than the ratio when it was less than one $\left(\mathrm{Wi} / \mathrm{Wo}_{0}<1\right)$. This indicates that the PKW with a higher value of Wi/Wo gives a higher value of discharge capacity ratio for a constant value of $(\mathrm{Ht} / \mathrm{P})$ which leads to the fact that the inlet key was the most efficient part of the PKW due to its combinations of the s lateral and frontal overflows. Moreover, the PKW type A with a value of $(\mathrm{Wi} / \mathrm{Wo}=2)$ gives a higher discharge capacity ratio than the other value of $(\mathrm{Wi} / \mathrm{Wo})(0.5,0.8,1$ and 1.25), this was more significant at $(\mathrm{Ht} / \mathrm{P}<0.4)$. The same result was obtained with less increase in the discharge capacity ratio at $(\mathrm{Ht} / \mathrm{P}>0.4)$. Therefore, increasing the width ratio (Wi/Wo) from 0.5 to 2 at $(\mathrm{Ht} / \mathrm{P}=0.4)$ tends to increase the discharge capacity ratio by $25 \%$. 


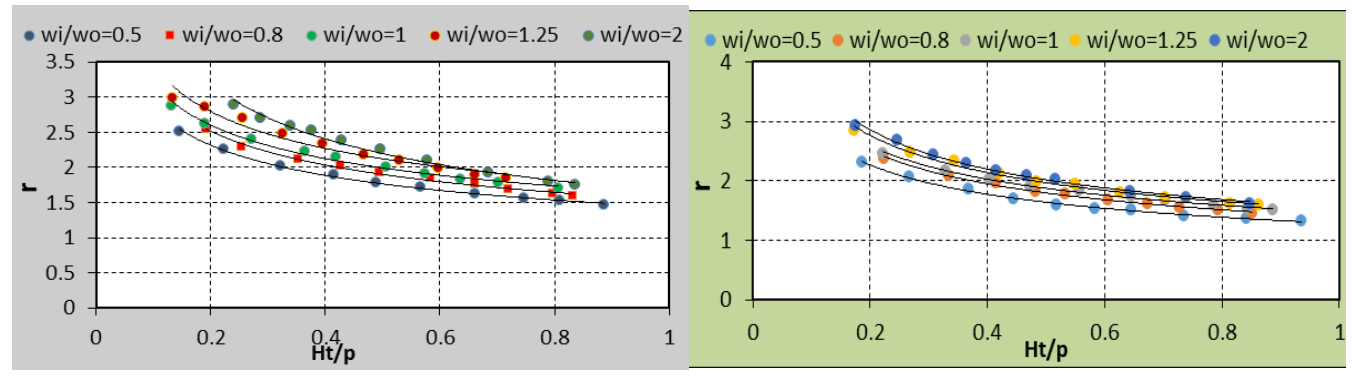

Left a) Relationship between (r) and (Ht/P) for different values of (Wi/Wo) for PKW type A. (right b) Relationship between (r) and (Ht/P) for different values of (Wi/Wo) for PKW type D

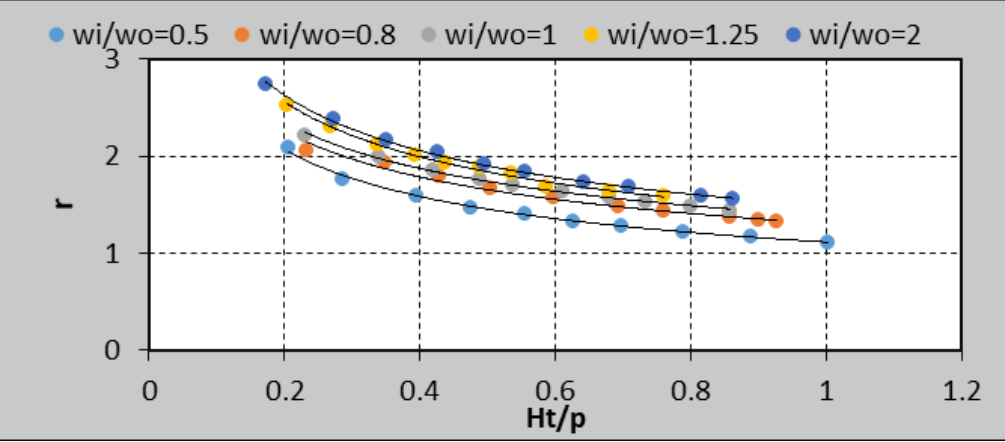

c) Relationship between (r) and (Ht/P) for different values of (Wi/Wo)for RL

Figures 5 Influence of (Wi/Wo ) ratios on discharge capacity ratio (r) for different types of piano key weirs.

\section{Effect of PKW height (P) on discharge capacity ratio.}

The effect of weir height on the relation between the discharge capacity ratio (r) and $\mathrm{Ht} / \mathrm{P}$ were studied. For this purpose, models were tested with different weir height $(\mathrm{P}=10 \mathrm{~cm}, \mathrm{P}=12 \mathrm{~cm}$, and $\mathrm{P}=14)$ keeping the parameters $(\mathrm{L} / \mathrm{W})$ and $(\mathrm{Wi} / \mathrm{Wo})$ ratios as constant for all types of piano key weirs, it was noted that there was no significant variation in the relation between discharge capacity ratio and $\mathrm{Ht} / \mathrm{P}$ as shown in Fig 6. This could be in regard to the fact that the influence could not be appeared due to the restriction of the channel dimensions and flow rate discharge capacity of the channel. 

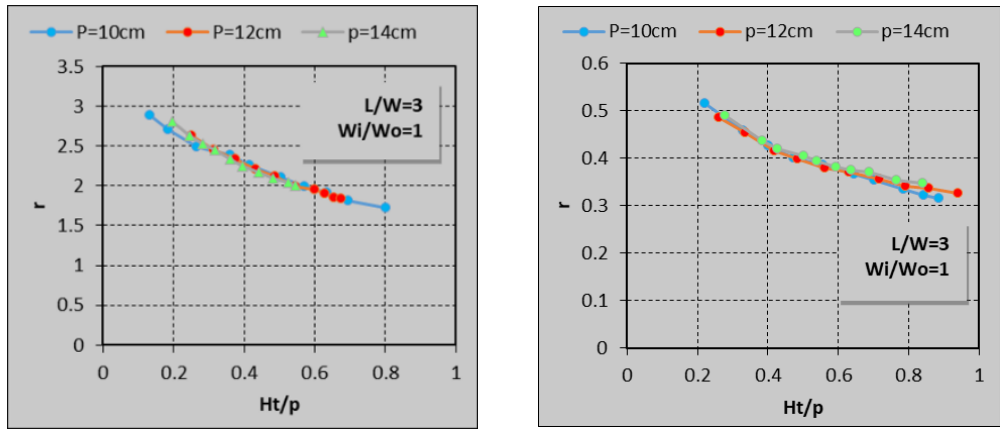

(left a) Relationship between discharge capacity ratio (r) and (Ht/p) for different $\mathbf{P}$ of type A PKW (right b) Relationship between discharge capacity ratio (r) and (Ht/p) for different $\mathbf{P}$ of type D

\section{PKW}

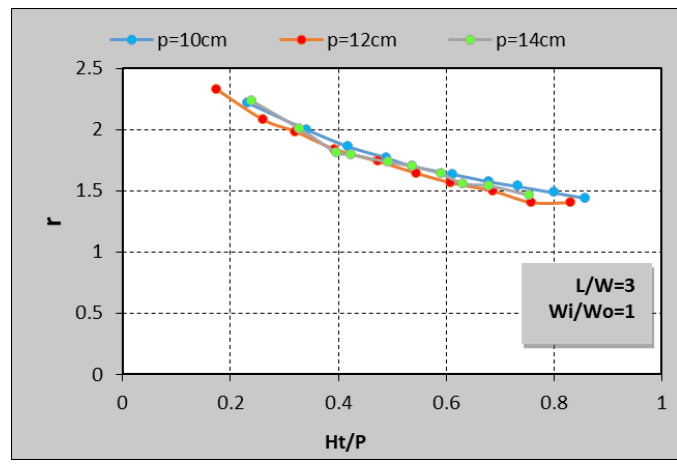

c. Relationship between discharge capacity Ratio (r) and (Ht/p) for different $\mathbf{P}$ of RLW

Figure 6 Influence of $(\mathbf{P})$ on discharge capacity ratio (r) for the different type of piano key weirs.

\section{Comparison between the types of PKW concerning discharge capacity ratio}

To find the influence of the dimensionless pi group terms on the discharge capacity ratio and which of the PKW types is more hydraulically efficient, a comparison between the three types of piano key weirs (PKW type A, PKW type D, and RLW ) was conducted. To illustrate the influence of the PK weir, overhangs in upstream and downstream place, floor slope on discharge capacity ratio and the relationship between the discharge capacity ratio and $(\mathrm{Ht} / \mathrm{P})$ were drawn as shown in fig. 7 . The discharge capacity ratio of these types of weir were compared to each other. Type A of PKW was found to be more efficient in producing discharge capacity ratio than type D of PKW due to the existence of the overhang in the upstream and downstream ends. Also, Type D of PKW was found to be more hydraulically efficient than RLW due to the existence of the floor slope. 


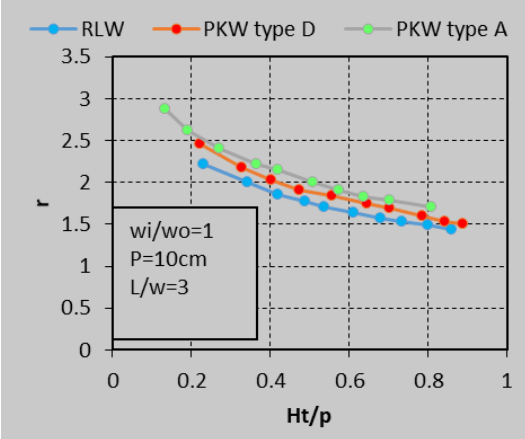

Fig 7a Variation of $r$ with $\mathrm{Ht} / \mathrm{p}$ for RLW type A and type D piano key weir.

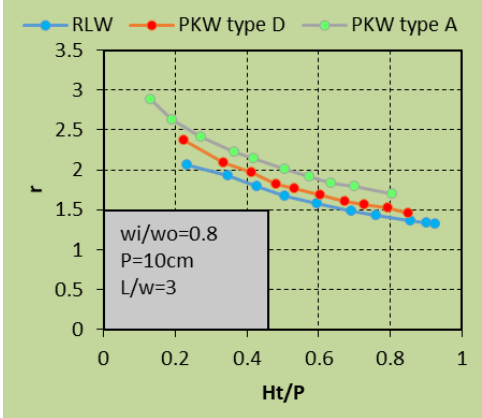

Fig7b Variation of $r$ with Ht/P for RLW, type A and type D piano key weir

\section{Correlations for Discharge capacity ratio (r)}

To obtain equations for the discharge capacity ratio ( $r$ ) for PKW type A, (SPSS20) statistical software was used to obtain two types of equations relating the discharge capacity ratio $(r)$ and the dimensionless parameters obtained from the dimensional analysis as mentioned previously, types of discharge capacity ratio equations can be stated as:

1. power function relationship between $(r)$ and the other parameters:

$$
r=1+0.186 *\left(\frac{H}{P}\right)^{-0.622}\left(\frac{W i}{W o}\right)^{0.353}\left(\frac{L}{W}\right)^{1.519}\left(\frac{B}{P}\right)^{-0.392}
$$

2. exponential power function relationship between $(r)$ and the rest of the parameters:

$$
r=e\left(\begin{array}{l}
0.37 *\left(\frac{H}{P}\right)^{-0.054}+0.369 *\left(\frac{H}{P}\right)^{-0.057}+1.268 *\left(\frac{W i}{W o}\right)^{0.087} *\left(\frac{H}{P}\right)^{-0.073}+0.01 *\left(\frac{L}{W}\right)^{1.322} \\
\left(\frac{H}{P}\right)^{-0.434}+0.009 *\left(\frac{L}{W}\right)^{1.56} *\left(\frac{H}{P}\right)^{-0.53}-1.123
\end{array}\right)-1
$$

\section{Comparison of study results with those of the other investigators}

To make sure that the result of this research is acceptable, it is important to compare the results of this study with those of other investigators. As most of the previous work done was on the discharge capacity ratio for flow passing over Piano Key Weir type A, the comparison will be restricted to the results of the PKE type A only. The equations of discharge capacity ratio (r) obtained by previous investigators are shown in Table 4.

Table 4 discharge capacity ratio equation of different investigator

\begin{tabular}{l|l} 
source & Discharge ratio equations
\end{tabular}




\begin{tabular}{|l|l|}
\hline $\begin{array}{l}\text { Leite } \\
\text { Ribeiro et } \\
\text { al.[3] }\end{array}$ & $\begin{array}{l}r=e\left(-0.25945\left(\frac{P}{W_{i}}\right)^{1.4}\left(\frac{H}{P}\right)^{0.15}+1.0056\left(\frac{L}{W_{i}}\right)^{0.1}\left(\frac{P}{W_{i}}\right)^{0.5}\left(\frac{H}{P}\right)^{0.7}\right. \\
\left.-0.067404\left(\frac{L}{W_{i}}\right)^{0.3}\left(\frac{P}{W_{i}}\right)^{0.1}\left(\frac{W_{i}}{W_{o}}\right)^{0.25}\left(\frac{H}{P}\right)^{0.2}+13.9156\left(\frac{L}{W}\right)^{0.35}\left(\frac{H}{P}\right)^{0.15}\right)-1 \\
-14.0239\left(\frac{L}{W}\right)^{0.35}\left(\frac{H}{P}\right)^{0.2}+0.094\end{array}$ \\
\hline $\begin{array}{l}\text { Leite } \\
\text { Ribeiro[10 }\end{array}$ & $r=1+0.24\left(\frac{(L-W) P i}{W H}\right)^{0.9}\left(\frac{P_{i}}{P_{o}}\right)^{0.25}\left(\frac{W_{i}}{W_{o}}\right)^{0.05}\left(0.3+\frac{B i+B o}{B}\right)^{-0.5}\left(1+\left(\frac{R o}{P o}\right)^{2}\right)$ \\
\hline $\begin{array}{l}\text { Present } \\
\text { study }\end{array}$ & $r=1+0.186 *\left(\frac{H}{P}\right)^{-0.622}\left(\frac{W i}{W o}\right)^{0.353}\left(\frac{L}{W}\right)^{1.519}\left(\frac{B}{P}\right)^{-0.392}$ \\
\hline
\end{tabular}

A comparison was carried out between the discharge ratios equation of this study and the discharge ratio equation of the other investigation. Figure 8 shows the comparison of the results for piano key weir type A with those of Leite Ribeiro [3], [10], which shows that the present study results lie well within the lines of the other investigators.

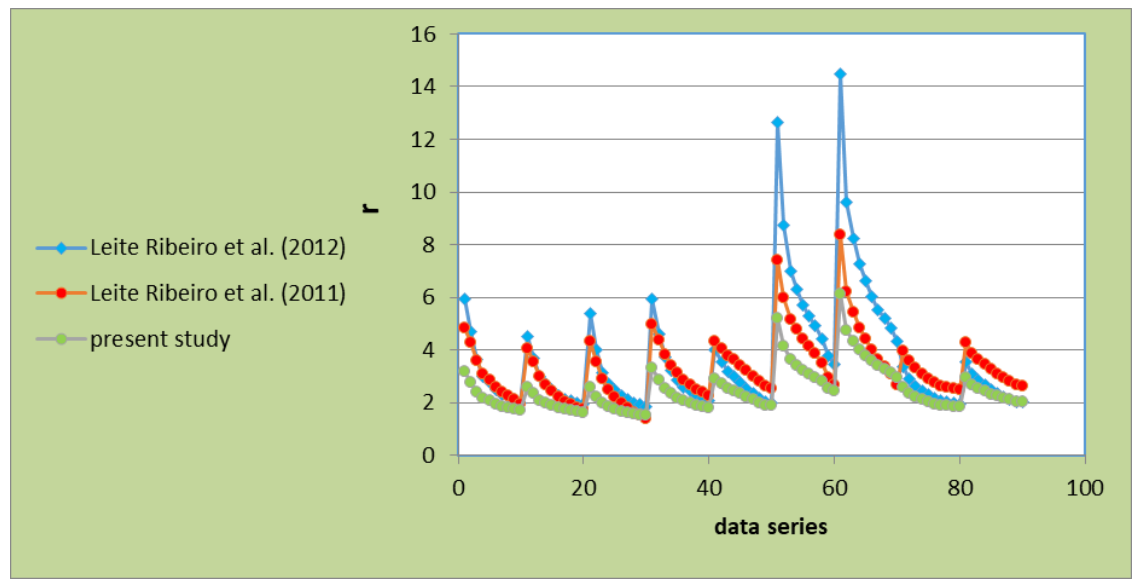

Fig. 8 Comparison of discharge capacity ratio of the present study with other investigators for type A PKW.

\section{Conclusions}

From the present experimental and theoretical study, the following points were concluded: 
1. PKW type A gives higher discharge capacity ratio (r) than PKW type D, due to the effect of overhangs and also PKW type D gives a higher value of discharge capacity ratio than the RLW due to the effect of the upstream and downstream slope.

2. PKW downstream overhang geometry provides a larger area and more wetted perimeter in the outlet keys in comparison to the rectangular labyrinth weir resulting in more discharge quantity at the outlet key exit.

3. The influence of (Wi/Wo) parameter on discharge capacity ratio of the PKW type A resulted in increasing the discharge capacity ratio by $25 \%$ when the value of (Wi/Wo) changed from 0.5 to 2 .

4. Increasing the head over PKW, resulted in discharge capacity ratio decrease because of the interference of the overflowing layer which leads to decrease in the total developed crest length ( $\left.\mathrm{L}_{\mathrm{eff}}\right)$ of PKW and then the PKW gradually behaves like a linear weir.

5. The discharge capacity ratio of PKW increases when increasing the value of (L/W), due to increasing the total developed crest length. It was found that the discharge capacity ratio for PKW type A may be increased by (27\%) when increasing the value of (L/W) from 3 to 7.

6. For all types of PKW, increasing in head over the PKW will increase the discharge.

7. The height of PKW (P) does not influence the hydraulic performance of $\mathrm{PKW}$ due to the restriction of the channel dimension and experimental channel flow capacity.

\section{References:}

[1] Anderson, R.M., "Piano Key weir head discharge relationships", MSc. Thesis, Department of Civil and Environmental Engineering, Utah State University. (2011)

[2] Anderson, R.M. and Tullis, B., "Comparison of Piano Key and rectangular Labyrinth Weir hydraulics”, Journal of Hydraulic Engineering, Volume 138, Issue 4, pp. 358-361. (2012)

[3] Leite Ribeiro M., Boillat J.L. and Schleiss A.J., "Experimental parametric study for hydraulic design of PKWs", Labyrinth and piano key weirs-PKW 2011, CRC Press, London, 183-190. (2011) [4] Leite Ribeiro, M., Bieri, M., Boillat, J.-L., Schleiss, A.J., Delorme, F. and Laugier, F., "Hydraulic capacity improvement of existing spillways - Design of Piano Key Weirs", in proc. of 23rd congress of CIGB/ICOLD, Q.90, R.43. Brasilia. (2009)

[5] Kabiri-Samani, A. and Javaheri, A., "Discharge coefficient for free and submerged flow over Piano Key weirs", Journal of Hydraulic Research, Volume 50, Issue 1, pp. 114-120. (2012)

[6] Lempérière F., Vigny J.P. and Ouamane A., "General comments on Labyrinths and Piano Key Weirs" The past and present, Labyrinth and piano key weirs-PKW 2011, CRC Press, London, 1724. (2011)

[7] Michael Pfister, Elena Battisacco, Giovanni De Cesare \& Anton J. Schleiss "Scale effects related to the rating curve of cylindrically crested Piano Key" weirs Laboratory of Hydraulic Constructions (LCH), Ecole Polytechnique Fédérale de Lausanne (EPFL), Station 18, CH - 1015 Lausanne, Switzerland. (2013)

[8] Othman Kurshed. "Flow Characteristics Through Pipe Culvert Combined with Broad Crested Weir" at the University of Salahaddin as partial requirements for the degree of Master of Science in Dams and Water Resources Engineering. (2003)

[9] Anderson, R.M. and Tullis, B. "Influence of Piano Key Weir geometry on discharge" Proc. Intl.

Conf. Labyrinth and Piano Key Weirs, Liège B, 75-80. CRC Press, Boca Raton FL. (2011) 
[10] Leite Ribeiro, M., Pfister, M., Schleiss A.J., and Boillat, J.-L. "Hydraulic design of A-type Piano Key Weirs", Journal of Hydraulic Research, Volume 50, Issue 4, pp. 400-408. (2012)

[11] Machiels, O., "Experimental study of the hydraulic behaviour of Piano Key Weirs." PhD Thesis ULgetd-09252012- 224610, University of Liège (B). (2012)

[12] Michael Pfister, Elena Battisacco, Giovanni De Cesare \& Anton J. Schleiss. "Labyrinth and Piano Key Weirs II." Laboratory of Hydraulic Constructions (LCH), Ecole Polytechnique Fédérale de Lausanne (EPFL), Station 18, CH - 1015 Lausanne, Switzerland CRC Press, Boca Raton. (2013) [13] Ouamane, A. \& Lempérière, F.," The piano keys weir: a new cost-effective solution for spillways." Hydropower \& Dams. 2003 